measured the success of the cafés by recording attendance rates and through conducting qualitative surveys.

Results Attendance rates: 2016: 19, 2017: 43, 2018: 82.

Conclusion During the three years of death cafés at Ashgate Hospicecare, there has been an evident growth in attendance rates. To complement this, the surveys have shown more positive feedback from death café attendees and growing interest from outside organisations who want to be involved in future events. Moving forward, Ashgate Hospicecare aims to run death cafés throughout the year, working in partnership with other community groups, such as schools and clinical organisations. We strongly believe in the importance of raising awareness around death and dying and helping people plan for their future.

\section{P-52 LEARNING FROM BEFRIENDERS IN COMPASSIONATE COMMUNITIES - SERVICE CO-PRODUCTION WITH VOLUNTEERS}

Tracy Livingstone. Nightingale House Hospice, Wrexham, UK

\subsection{6/bmjspcare-2018-hospiceabs.77}

'Compassionate Communities help to reduce isolation and loneliness and bring a sense of belonging into what is sometimes a disconnected society.' (Abel \& Kingston, 2018).

Nightingale House Hospice in Wrexham, North Wales covers a diverse catchment area including urban, coastal and rural communities, and includes areas of significant deprivation (Jones, Atenstaedt \& Charles, 2014).

During 2015, following the pilot of a day unit outreach service within a local, rural community, the hospice supported the community to develop a compassionate communities befriending project, and this was followed by two further befriending groups in other communities within our catchment area.

Our presentation describes a service evaluation undertaken with our volunteers from these three compassionate communities groups to identify the motivation for volunteers to become befrienders, their own social circumstances and households and how to improve the establishment of compassionate communities from the perspective of the volunteers delivering the service. The presentation identifies the enthusiasm from the volunteers to deliver a service to others and also the challenges of ensuring systems to ensure befriender safety are in place. The presentation concludes by demonstrating how the feedback from volunteers has impacted on the training delivered, in a demonstration of co-production and the systems for establishing new groups with ten active groups now in development or operation.

\section{Generating research, knowledge and outcomes}

\section{P-53 TRANSFORMING PALLIATIVE CARE SERVICE THROUGH DATA COLLECTION, ANALYSIS AND SHARING}

Karolyn Hallam. Isabel Hospice, Welwyn Garden City, UK

10.1136/bmispcare-2018-hospiceabs.78
Background How is data used to really understand the service that we provide, help target service delivery and assist the development of a clinical strategy to enhance care provision?

Aims Review historical data for gaps in service provision. Identify meaningful data to inform hospice strategy and vision of supporting more people, earlier. Monitor, benchmark our progress and share with staff.

Method We undertook a review of historical data and health needs analysis to identify gaps in service provision. Analysis showed a diverse palliative service user population with patients being referred late in their diagnosis and a small cohort of non-cancer patient referrals, highlighting a gap in specialist palliative intervention. With OACC measures fully embedded in clinical practice, we asked how patient reported outcomes could be used to improve patient care and reflected on IPOS scores quarterly, which showed patients scoring highly in relation to the psychological impact of their illness. We introduced specialist link nurses and expanded our day services to encourage early referrals; a daily morning community meeting to identify, discuss and prioritise those patients with an unstable phase of illness and increased provision of psychological and spiritual support in our family support team.

Results Increased non-cancer referrals into the hospice from $19 \%$ to $40 \%$; reduction of cancer patients dying within one month of referral from $39 \%$ to $35 \% ; 10 \%$ reduction in the percentage of patients scoring severely or overwhelmingly for psychological concerns at the end of spell of care; 18 day average for a patient to move from unstable to stable phase following CNS intervention.

Conclusion Clinical data acts as a vital tool for identifying where action may be needed to address gaps in care delivery. Sharing these outcomes with clinical managers and staff helps everyone to understand the importance of accurate and meaningful data.

\section{P-54 TRANSFORMING SPECIALIST PALLIATIVE CARE WITH DATA}

Duncan Newberry, Collins Okakwu, Laura Myers. Sue Ryder, Nettlebed, UK

\subsection{6/bmispcare-2018-hospiceabs.79}

Background Interprofessional working is vital in the delivery of specialist palliative care (Dawson, 2007); both between and within organisations. Funding bodies require ever stronger evidence before and after gifting monies, and technology is showing potential for the identifying patients in need of palliative care (Tanuseputro, 2017). Use of data has proved problematic in palliative care, leading some to highlight the importance of making the most of routine data (Hanratty, Goldacre, Griffith, et al., 2008).

Aims To evaluate how data are being generated, gathered and used in different areas of the hospice, and the role of technology in this (Nwosu, Collins \& Mason, 2018).

Methods A Clinical Support Analyst position has been created to collate data. To demonstrate the range of educator activity, the Clinical Practice Facilitator (CPF) has been using an app (WonderApps AB, 2018) to collate data about his time division. Registrations onto courses are made through an electronic booking system (Eventbrite). Education evaluation data is collated electronically and brought 